\title{
Children's memory for sentences and word strings in relation to reading ability
}

\author{
VIRGINIA A. MANN, ISABELLE Y. LIBERMAN, and DONALD SHANKWEILER \\ Haskins Laboratories, New Haven, Connecticut 06510
}

\begin{abstract}
A previous study of recall of letter strings by good and poor beginning readers (Shankweiler, Liberman, Mark, Fowler, \& Fischer, 1979) revealed that the performance of good readers was more severely penalized than that of poor readers when the letter names rhymed. To determine whether the differences in susceptibility to phonetic interference extend to materials that more closely resemble actual text, we designed an experiment to test recall of phonetically controlled sentences and word strings. As in the case of letter recall, we found that, although good readers made fewer errors than poor readers when sentences or word strings contained no rhyming words, they did not excel when the materials contained many rhyming words. In contrast to manipulations of phonetic content, systematic manipulations of meaningfulness and variations in syntactic structure did not differentially affect the two reading groups. We conclude that the poor readers' inferior recall of phonetically nonconfusable sentences, word strings, and letter strings reflects failure to make full use of phonetic coding in working memory.
\end{abstract}

Much evidence suggests that adult subjects employ a phonetic representation during comprehension of both spoken and written material (see, for example, Baddeley, 1978; Kleiman, 1975; Levy, 1977; Liberman, Mattingly and Turvey, 1972; Tzeng, Hung, and Wang, 1977). In several studies of beginning readers, we and other investigators (Byrne \& Shea, 1979; Mark, Shankweiler, \& Liberman, 1977; Shankweiler, Liberman, Mark, Fowler, \& Fischer, 1979) have found new support for the involvement of phonetic representation in the reading process: The ability to make effective use of phonetic representation appears to be correlated with success at learning to read.

The possibility of associating children's reading ability with their use of phonetic representation was explored first by Liberman, Shankweiler, and their colleagues (Liberman, Shankweiler, Liberman, Fowler, \& Fischer, 1977), who assessed the role of phonetic representation in letter string memory. Using a modification of Conrad's (1964) procedure, they asked good and poor readers in the second grade to recall a string of consonants in which the letter names either

The second and third authors are also at the University of Connecticut, Storrs. This work was partially supported by a grant from the National Institute of Child Health and Human Development (Grant HD-01994) to Haskins Laboratories and by a NICHD postdoctoral fellowship (Fellowship HD05677) to Virginia Mann. Thanks are due Robert Katz, who also aided in testing the reading ability and IQ. Bruno Repp and Leonard Katz provided helpful assistance with the statistical treatment of the data. We also wish to express our appreciation for the generous cooperation of the staff of the Parker Memorial School in Tolland, Connecticut. Special thanks are due the principal, Robert Lincoln; the three second-grade teachers, Judy Lombard, Diane Iadoresta, and Jean Medick; and the school secretary, Florence Peacock. We are also grateful to the children who participated and to the parents, without whose permission we could not have proceeded. rhymed or did not. In both the rhyming and nonrhyming conditions, good readers recalled more items than poor readers. However, the good readers, like Conrad's adult subjects, were greatly penalized by rhyme, whereas the poor readers performed at about the same level on both rhyming and nonrhyming strings. A subsequent experiment (Shankweiler \& Liberman, 1976) showed that the same pattern of recall performance occurred whether the items were presented by eye or by ear. The interaction of reading ability and the effect of phonetic confusability has also been demonstrated for recognition memory of isolated words, where good readers show evidence of greater reliance on phonetic representation as a means of remembering words presented in either written (Mark et al., 1977) or spoken (Byrne \& Shea, 1979) form. In sum, these findings indicate that underlying poor readers' defective performance is a problem extending beyond the act of recording from print to speech, involving a more general deficit in the use of phonetic coding in working memory.

Consonant strings and isolated words, however, are far removed from actual text. It remains to be determined whether good or poor readers' recall of more natural linguistic stimuli will be affected by the same experimental variables. Accordingly, this investigation extends previous work on the effect of phonetic confusability to a more ecologically valid situation involving sentence and word recall. Previous findings in the research literature have suggested that poor readers' recall of both sentences (Mattis, French, \& Rapin, 1975; Perfetti \& Goldman, 1976; Weinstein \& Rabinovitch, 1971; Wiig \& Roach, 1975; Pike, Note 1) and word strings (Bauer, 1977b; Katz \& Deutsch, 1964) is inferior to that of good readers. While inferior sentence recall has often been attributed to difficulty in recovering syntactic structure (see, for example, 
Mattis et al., 1975; Weinstein \& Rabinovitch, 1971; Pike, Note 1), recall difficulties with word strings have been attributed to inadequate rehearsal strategies (Bauer, $1977 \mathrm{~b}$ ). In our investigations, however, we proceeded from the view that inferior recall of both sentences and word strings might have a unitary underlying cause, the same difficulty with phonetic representation that leads to inferior letter string recall. In this light, we supposed that introducing phonetically confusable words into a sentence or word string would differentially affect children who differ in reading ability.

We therefore assessed children's ability to recall sentences which vary not only along the traditional dimensions of syntax and meaning (as in Miller \& Isard, 1964), but also in the presence of phonetically confusable words. Our materials included seven different syntactic constructions, each of which is presented in four versions: a meaningful version in which none of the words rhyme, a meaningful version in which the majority of words rhyme, a meaningless version in which words do not rhyme, and a meaningless version in which most words again rhyme. The recall of word strings is examined in an analogous fashion, with items containing five words selected from the meaningless versions of the test sentences. In half of these, the words do not rhyme; in half, they do.

\section{METHOD}

\section{Subjects}

The subjects were second-grade children from a public school in suburban Connecticut. An initial subject pool of 15 good and 15 poor readers was obtained by means of teacher recommendations and scores on the word recognition subtest of the Comprehensive Test of Basic Skills (1974), which had been administered at the end of the first grade. The reading ability of subjects selected in this way was assessed by administration of the Word Attack and Word Identification subtests of the Woodcock Reading Mastery Test (Woodcock, 1973). The mean sum of error scores on these subtests was 54.2 for good readers, as compared with 133.9 for poor readers $[\mathrm{t}(28)=18.19, \mathrm{p}<.001]$. There was no overlap between scores of the two groups. The subjects had IQ scores ranging between 90 and 135 on the Slosson Intelligence Test (Slosson, 1963). The mean IQ score for good readers (114.7) was marginally superior to that of poor readers $(107.6)[t(28)=1.6$ $p<.06]$. The two groups were not significantly different in mean age: 96.3 months for the good readers, 97.1 for the poor readers. All children had been screened by the school system and found to be free from speech or hearing disorders.

\section{Materials}

Sentences. Items for the sentence repetition task were permutations of seven 13-word English sentence forms. These seven base structures were chosen to represent a variety of English constructions, with complexity varied along a number of syntactic dimensions. The adoption of the length of 13 words was motivated by a desire to prevent good readers from achieving ceiling performance, since ceiling performance confounds interpretation of many previous studies of the sentence recall of good and poor readers. Prior to designing the sentence repetition materials, we conducted a pilot study of the effect of sentence length on the sentence recall of eight average readers in the second-grade classrooms from which the subjects were drawn. Results indicated that average readers began to make errors as the length of a meaningful, phonetically nonconfusable sentence approached 13 words.

Each structure was presented in four versions, which were constructed by substitutions among content words, with position and choice of function words held constant. Thus, syntactic structure was the same across the four versions of each base, while manipulations of content words permitted orthogonal variation of meaningfulness and phonetic confusability. Versions were meaningful/phonetically nonconfusable, meaningful/phonetically confusable, meaningless/phonetically nonconfusable, or meaningless/phonetically confusable.

All versions of each base sentence were matched with respect to word frequency (Thorndike and Lorge, 1944) and the number of syllables contained in each word. The meaningless versions differed from meaningful ones with respect to whether choice of nouns, verbs, and adjectives adhered to semantic restrictions. Meaningful versions were created in accordance with these restrictions; meaningless versions were created by violating them. The phonetically nonconfusable and phonetically confusable versions differed with respect to the presence of rhyming items. Phonetically nonconfusable versions contained no rhyming words; phonetically confusable versions contained from seven to nine rhyming words. The number of rhyming words and their position were held constant across the two phonetically confusable versions of each base. All versions of the seven sentence forms are listed in the Appendix.

Word strings. The word strings consisted of words obtained from the meaningless phonetically nonconfusable version and the meaningless phonetically confusable version of the sentences used in the sentence repetition task. For each string, a set of five words was chosen from among the one-syllable content words of one version. (In the case of phonetically confusable versions, choice was limited to rhyming words.) Each set of five words was then rearranged to form an agrammatic sequence, a manipulation that resulted in a final set of 14 five-item agrammatic word strings, seven of which contained words that rhymed and seven of which were made up entirely of nonrhyming words.

\section{Procedure}

Both the sentence repetition and word string repetition tasks were conducted within a single 20 -min session, with all subjects receiving the sentence repetition materials first. Transcriptions of each subject's responses were made during the experimental session by the examiner and later checked against a tape recording of the child's responses.

The test session was preceded by a training procedure designed to assure that the child understood the task. The examiner explained that the child was to listen to a sentence and then try to repeat it, even if the sentence seemed strange. She stressed that the important thing was for the child to repeat as many words as possible, guessing or skipping over some parts if necessary. The child was then presented with a set of four practice items: two 13-word meaningful phonetically nonconfusable sentences and two 13-word meaningless phonetically nonconfusable ones. The experimenter read each sentence twice, after which the child was asked to repeat the sentence. If the child made no attempt to respond, the sentence was read a third time; children who hesitated over a word were encouraged to guess or to skip over that word. On completion of the four practice items, the child was advised that he would next be listening to a prerecorded series of the test sentences. That series included four versions of each of the seven base sentences, arranged in a fixed random order. Each sentence was repeated twice by a male, native American speaker of English, who attempted to hold prosody constant across the four versions of each base sentence. During actual testing, there was no prompting for responses, nor were unrecalled sentences repeated a third time. 
After completion of the test sentences, the child was allowed a brief rest before the word string repetition task was administered. During this break, the examiner explained that the next test involved listening to a series of five words and then trying to repeat that series. She then played a prerecorded set of the 14 five-item word strings. Like the sentences, they were presented in a fixed random order and were spoken by the same male speaker. However, unlike the sentences, each string was read only once. Words within the string were read at the rate of $1 / \mathrm{sec}$ with prosody held neutral.

\section{Scoring Procedure}

Sentences. The error scores were the sum of omissions, substitutions, and reversals made on each version of each base sentence. All versions were scored in the following manner: A score of zero was given for correct repetition with no errors. One point was given for each word recalled in the improper sequence (relative to the preceding word), for each substitution, and for each intrusion. Words that followed substitutions or intrusions were scored relative to the immediately preceding word that had been a member of the original sentence. A score of 13 was given when a subject failed to repeat any of the words of the sentence.

Word strings. For word strings, as for sentences, the error score was the sum of omissions, substitutions, and reversals. To minimize the effects of guessing, only the first five words produced during recall were counted. A score of zero was given if all items were recalled in proper order. One point was given for each word recalled in the improper order, and for each substitution and intrusion. Words preceded by a substitution were scored relative to the immediately preceding member of the sequence. A score of five was given if the subject failed to recall any of the items.

\section{RESULTS}

This experiment was conducted to determine whether the verbal memory of good and poor readers would be differentially affected by systematic variations in phonetic confusability of the material to be recalled. For this purpose, memory for sentences and for agrammatic word strings was examined separately. The effects of systematic variations in meaningfulness were also examined in the case of sentence memory, as was the effect of variations in syntactic structure.

\section{Sentence Repetition}

In considering sentence memory, we needed first to ascertain that our good and poor readers could be differentiated by their overall performance on our materials. To this end, error score data on all the sentence versions were subjected to an analysis of covariance with IQ controlled. It was found, as expected, that good readers made fewer errors overall than poor readers. The mean error score for good readers was 4.7 , as compared with 5.3 for poor readers $\left[\mathrm{F}_{\mathrm{IQ}}(1,27)=7.6, \mathrm{p}<.01\right]$. Another prior requirement was to determine whether the stimulus variations we had introduced had any differential effects on the performances of the two groups. Each of the sentences had been presented in four versions which varied orthogonally in phonetic confusability and meaningfulness. As can be seen in Figure 1, in which mean error scores on each version type are

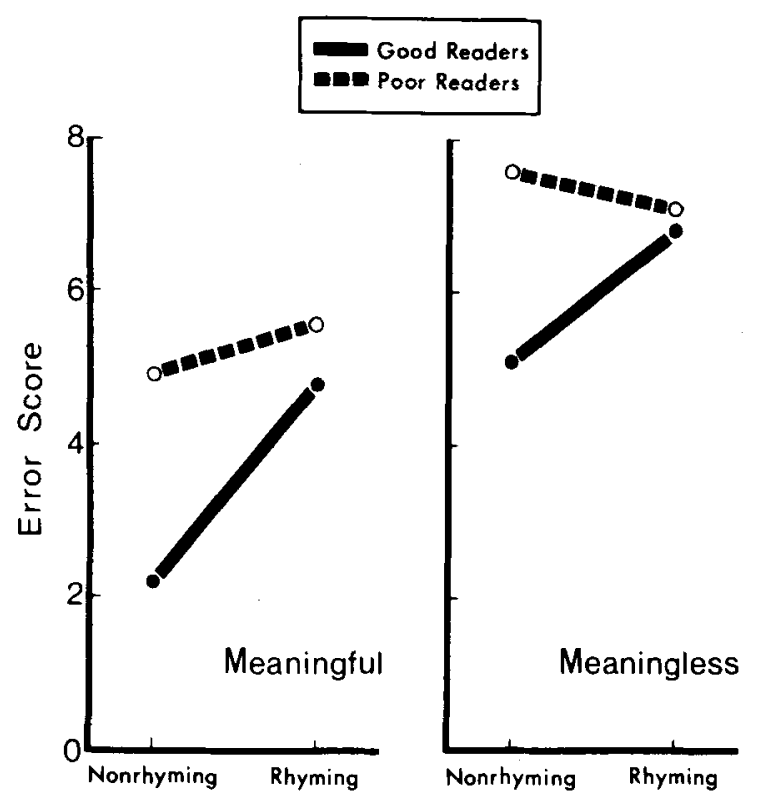

Figure 1. Good and poor readers' mean error scores (maximum $=13$ ) on meaningful and meaningless sentence versions, in nonrhyming and rhyming conditions.

separately plotted, there were more errors on rhyming versions than on nonrhyming versions $\left[\mathrm{F}_{\mathrm{IQ}}(1,28)=\right.$ $124.5, \mathrm{p}<.001]$. Meaningfulness also produced a significant effect $\left[\mathrm{F}_{\mathrm{IQ}}(1,28)=172.6, \mathrm{p}<.001\right]$.

Having established that the good and poor readers did indeed differ in sentence memory and that there were effects of the stimulus variations, we turned next to the central focus of this study, which is the interaction between the stimulus variables and reading ability. We found that good readers were affected by phonetic confusability to a markedly greater extent than poor readers $\left[F_{I Q}(1,27)=90.9, p<.001\right]$. No such interaction was obtained for the variable of meaningfulness. Supplementary analysis by t test permitted us further to assess mean differences between the two groups on each of the four sentence versions. Here, as in the overall analysis, good readers averaged significantly fewer errors than poor readers on the phonetically nonconfusable versions, both meaningful [ $\mathrm{t}(12)=$ $4.2, \mathrm{p}<.001]$ and meaningless $[\mathrm{t}(12)=5.1, \mathrm{p}<.005]$. In contrast, when the items were phonetically confusable, the performance of the good readers actually dropped to the level of that of the poor readers. Thus, in recall of the rhyming versions, both meaningful and meaningless, the performance of the good and poor readers did not differ significantly, as is depicted in Figure 1.

The consistency of these effects across individual sentences is revealed in Tables 1 and 2, where mean error scores are given for meaningful and meaningless versions, respectively. Although the extent of the effect of phonetic confusability varied across sentences $[F(1,168)$ $=5.9, \mathrm{p}<.001]$, as did the effect of meaningfulness 
Table 1

Mean Error Scores on Meaningful Sentence Versions

\begin{tabular}{cccccc}
\hline & \multicolumn{2}{c}{ Nonrhyming } & & \multicolumn{2}{c}{ Rhyming } \\
\cline { 2 - 3 } \cline { 5 - 5 } Sentence & $\begin{array}{c}\text { Good } \\
\text { Readers }\end{array}$ & $\begin{array}{c}\text { Poor } \\
\text { Readers }\end{array}$ & $\begin{array}{c}\text { Good } \\
\text { Readers }\end{array}$ & $\begin{array}{c}\text { Poor } \\
\text { Readers }\end{array}$ \\
\hline 1 & 2.6 & 5.7 & 4.2 & 5.1 \\
2 & 1.8 & 5.2 & 5.6 & 6.2 \\
3 & 1.4 & 3.8 & 6.9 & 6.1 \\
4 & 2.6 & 4.8 & 5.1 & 6.5 \\
5 & 2.0 & 4.4 & 2.8 & 4.5 \\
6 & 4.1 & 7.1 & 7.4 & 7.5 \\
7 & .8 & 3.8 & 2.4 & 3.2 \\
\hline
\end{tabular}

Table 2

Mean Error Scores on Meaningless Sentence Versions

\begin{tabular}{cccccc}
\hline & \multicolumn{2}{c}{ Nonrhyming } & & \multicolumn{2}{c}{ Rhyming } \\
\cline { 2 - 3 } \cline { 5 - 6 } Sentence & $\begin{array}{c}\text { Good } \\
\text { Readers }\end{array}$ & $\begin{array}{c}\text { Poor } \\
\text { Readers }\end{array}$ & $\begin{array}{c}\text { Good } \\
\text { Readers }\end{array}$ & $\begin{array}{c}\text { Poor } \\
\text { Readers }\end{array}$ \\
\hline 1 & 6.0 & 8.1 & 8.0 & 8.9 \\
2 & 5.2 & 6.9 & 8.4 & 8.4 \\
3 & 5.9 & 8.0 & 8.6 & 7.5 \\
4 & 5.3 & 7.1 & 4.8 & 4.8 \\
5 & 4.9 & 7.7 & 6.9 & 7.3 \\
6 & 6.1 & 8.5 & 6.9 & 7.9 \\
7 & 3.1 & 6.2 & 4.4 & 5.0 \\
\hline
\end{tabular}

$[F(1,168)=8.2, p<.001]$, there was no three-way interaction of reading ability, phonetic confusability, and type of base sentence or of reading ability, meaningfulness, and type of base sentence. An additional analysis was carried out to treat base sentence as a random variable nested within phonetic confusability and meaningfulness (see Clark, 1973). A significant interaction of reading ability and phonetic confusability was upheld $\left[\min F_{10}^{\prime}(1,31)=4.3, p<.05\right]$, but there was no significant interaction of reading ability and meaningfulness.

We turned finally to compare performance across the seven base sentences, a comparison which is not central to our purposes but is nevertheless permitted by our design. Since the base sentences were chosen to vary along a number of syntactic dimensions, it was expected that error rates in recalling them would differ. This expectation was confirmed $[\mathrm{F}(1,168)=29.3$, $\mathrm{p}<.001]$. There was, however, no significant interaction of reading ability and the effects of base sentence, showing that good and poor readers in our sample were comparably affected by the syntactic variations. A comparison of the distribution of errors made by good and poor readers on each of the four versions of each sentence provides further evidence that the two groups reacted similarly to variations in syntactic structure. The frequency of errors as a function of the position of words in the sentence was significantly correlated for the two groups in most versions $[\mathrm{r}(13)>.46, \mathrm{p}<.05$ for 26 of the 28 versions; $r(13)>.68, p<.005$ for 21 of them]. Thus, the errors of good and poor readers were similarly distributed, differing only in frequency of occurrence.

\section{Word Strings}

As was the case with the sentence repetition data, error scores on word string recall were subjected to an analysis of covariance with IQ controlled. Mean scores for good and poor readers are plotted in Figure 2 . It may be seen that an overall difference in error score was again found for good and poor readers $\left[\mathrm{F}_{\mathrm{IQ}}(1,27)=4.50, \mathrm{p}<.05\right]$. Also apparent once more is a significant effect of phonetic confusability $[F(1,28)=12.8, p<.002]$. The crucial interaction of reading ability and the effects of phonetic confusability was again strongly manifest $\left[\mathrm{F}_{\mathrm{IQ}}(1,27)=9.5\right.$, $\mathrm{p}<.002$ ]. As illustrated in Figure 2, the performance of good readers was markedly impaired by phonetic confusability, while that of the poor readers was not.

A test was made of the generality of these findings by an analysis of variance, with word string treated as a random variable. Here, as in the preceding analysis of covariance, the interaction of reading ability and phonetic confusability was significant $\left[\mathrm{F}_{\mathrm{IQ}}^{\prime}(1,14)=5.71, \mathrm{p}<.05\right]$.

\section{DISCUSSION}

As we noted in the introduction, a number of studies in the research literature report that unskilled readers tend to perform more poorly than skilled readers in short-term recall of letter strings, word strings, and sentences. In studies of letter string recall (Liberman et al., 1977; Shankweiler \& Liberman, 1976), demonstrations of the greater vulnerability of good readers to the effects of phonetic confusability suggest that these children place greater reliance on phonetic coding as a short-term memory strategy. Our aim in the present study was to test the generality of this interpretation by asking whether phonetic confusability also differentially affects good and poor readers' recall of not only

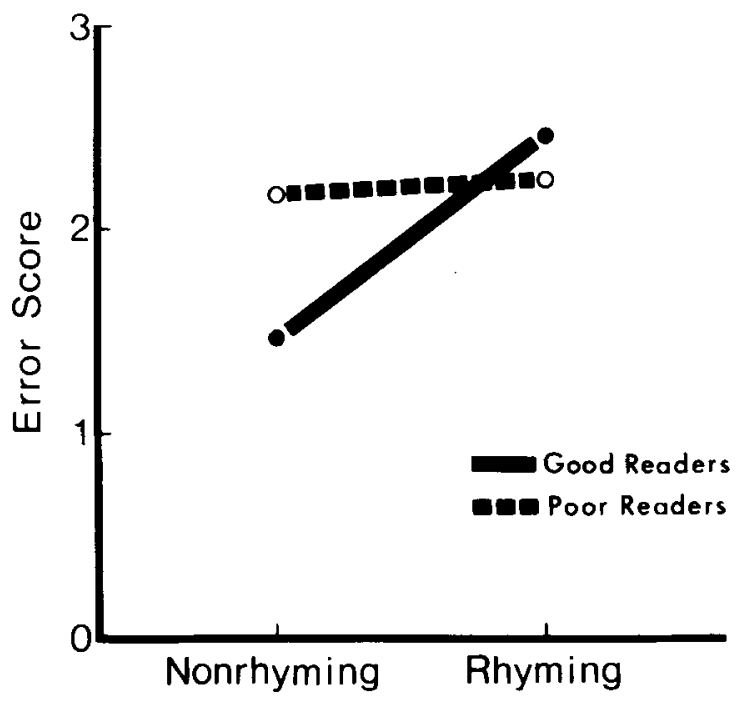

Figure 2. Good and poor readers' mean error scores (maximum $=5$ ) on word strings, in nonrhyming and rhyming conditions. 
alphabetic strings, but also of sentences and word strings.

To this end, good and poor readers in a second-grade sample were asked to repeat specially designed sentences and agrammatic word strings. Consistent with previous reports, good readers were better than poor readers when the material to be recalled, whether sentences or word strings, contained no phonetically confusable words. In contrast, the performance of good readers fell to the level of poor readers when phonetically confusable words were present. Although some studies have found that poor readers are more adversely affected than good readers by manipulations that destroy meaningfulness (Wiig \& Roach, 1975; Pike, Note 1, Note 2), our systematic variations of meaningfulness and syntactic structure did not differentially affect the two reading groups. Thus, we find no support for the conjecture that the poor reader's difficulty with sentence recall derives from difficulty with the recovery of syntactic structure per se. The primary distinction, once again, was that good readers were severely impaired by the introduction of phonetic confusability and the poor readers were not.

These findings confirm the results of Liberman et al. (1977) and extend them to the more natural task of sentence recall. Since the same pattern of interaction with phonetic confusability has been found for three different classes of items-letters, words, and sentences-a common etiology is implicated. We follow Liberman et al. (1977) in suggesting that the poor readers' substandard recall of verbal material may be caused by failure to make effective use of phonetic coding in working memory. Although the substandard recall of letter and word strings by poor readers has also been attributed to a failure to rehearse information held in short-term storage (see Bauer, 1977a, 1977b), our informal observation is that poor readers do, in fact, rehearse. Perhaps they appear guilty of rehearsal failure because they are rehearsing badly encoded information.

We have viewed these findings of correlation between effective use of phonetic coding and success at learning to read as further indication of the ubiquitous involvement of speech coding in the reading process. It could be supposed, however, that ineffective phonetic coding is a by-product rather than a determinant of reading difficulty. This question might be laid to rest if it could be shown that deficient use of phonetic coding in preschool children is predictive of reading failure, both in English and in languages that manifest quite different morphologies and writing systems. We are in the process of gathering data pertinent to this issue.

Other investigators have commented on the association between reading difficulty and deficient verbal short-term memory (see, for example, Perfetti \& Goldman, 1976; Perfetti \& Lesgold, 1979; Vellutino, Steger, DeSetto, \& Phillips, 1975; Vellutino, Steger, Kaman, \& DeSetto, 1975). Moreover, we are not alone in supposing that these dificiencies apply to perception of language by ear as well as by eye. Our supposition that a number of memory-related problems may be seen as manifestations of deficient phonetic coding (Shankweiler et al., 1979) is consistent with the views of Perfetti and his colleagues. It is appropriate at this point to consider what precisely might be the basis of the poor reader's limitations in the use of phonetic representation. In a recent paper (Shankweiler et al., 1979), we raised the question whether the deficits may extend beyond the memorial aspects of language, involving perhaps the level of perceptual encoding. If so, then sufficiently stringent tests of speech perception might be expected to distinguish good and poor readers of the sort studied here. We are currently investigating this possibility, bearing in mind the hypothsis of Perfetti and Lesgold (1979) that the short-term memory differences between good and poor readers may largely derive from slower encoding on the part of poor readers.

At the same time we are led to consider the basis of the poor reader's ineffective use of phonetic coding, we are also led to speculate as to its broader implications. We are guided by the assumption that a major function of phonetic coding in both written and spoken language is to facilitate interpretation of stretches of discourse longer than the word. If poor readers do, in fact, fail to make effective use of phonetic coding, then they may have difficulty comprehending some kinds of sentences in situations in which working memory is stressed.

We conclude by suggesting two ways in which working memory might be stressed in sentence processing. First, it may be stressed when recovery of syntactic structure requires retention of many component words of a sentence. Such could be the case in center-embedded sentences and sentences involving extensive movement or deletion, or in subordinate clauses headed by "that" (see Frazier \& Fodor, 1978; Kimball, 1975, for a discussion of sentence parsers). Accordingly, these might pose more difficulty for poor readers than for good readers. Second, even when syntactic structure is relatively simple, working memory may be stressed if word order is in some way crucial. The importance of word order in this sense has been discussed by Baddeley (1978) and is exemplified in the Token Test of DeRenzi and Vignolo (1962). We suspect that Token Test instructions, such as "Touch the large, red triangle with the small, green square," might differentiate between good and poor readers, and we intend to pursue this possibility. 


\section{REFERENCE NOTES}

1. Pike, R, Memory for words and reading ability. Paper presented at the Biennial Meeting of the Society for Research in Child Development, New Orleans, 1977.

2. Pike, R. Linguistic development as a limiting factor in learning to read. Paper presented at the First Annual Boston University Conference on Language Development, Boston, 1976.

\section{REFERENCES}

BADDELEy, A. D. The trouble with levels: A reexamination of Craik and Lockhart's framework for memory research. Psychological Review, 1978, 85, 139-152.

BAUER, R. Short-term memory in learning disabled and nondisabled children. Bulletin of the Psychonomic Society, 1977, 10, 128-130. (a)

BAUER, R. Memory processes in children with learning disabilities. Journal of Experimental Child Psychology, 1977, 24, 415-430. (b)

Byrne, B., \& ShEA, P. Semantic and phonetic memory in beginning readers. Memory \& Cognition, 1979, 7, 333-341.

Clank, H. H. The language-as-fixed-effect fallacy: A critique of language statistics in psychological research. Journal of Verbal Learning and Verbal Behavior, 1973, 12, 335-359.

Comprehensive Test of Basic Skills. Monterey, Calif: CTB/ McGraw-Hill, 1974.

ConRad, R. Acoustic confusions in immediate memory. British Journal of Psychology, 1964, 55, 75-84.

Corkin, S. Serial-order deficits in inferior readers. Neuropsychologia, 1974, 12, 347-354.

DEHIRSCH, K. Tests designed to discover potential reading difficulties at the six-year-old level. American Journal of Orthopsychiatry, 1957, 27, 566-576.

DeRenzi, E.. \& Vignolo, L. A. The Token Test: A sensitive test to detect receptive disturbances in aphasia. Brain, 1962, 85, 665-678.

Farnham-Diggory, S., \& GregG, L. W. Short-term memory function in young readers. Journal of Experimental Child Psychology, 1975, 19, 279-298.

Frazier, L., \& Fodor, J. D. The sausage machine: A new twostage parsing model. Cognition, 1978, 6, 291-325.

KAtz, P. A., \& Deutsch, M. Modality of stimulus presentation in serial learning for retarded and normal readers. Perceptual and Motor Skills, 1964, 19, 627-633.

KLEIMAN, G. M. Speech recoding in reading. Journal of Verbal Learning and Verbal Behavior, 1975, 14, 323-339.

Kimball, J. Predictive analysis and over-the-top parsing. In J. Kimball (Ed.), Syntax and semantics (Vol. 4). New York: Academic Press, 1975.

LEVY, B. A. Reading: Speech and meaning processes. Journal of Verbal Learning and Verbal Behavior, 1977, 16, 623-638.

Liberman, A. M., Mattingly, I. G., \& Turvey, M. Language codes and memory codes. In A. W. Melton \& E. Martin (Eds.), Coding processes and human memory. Washington, D.C: Winston, 1972

Liberman, I, Y., Shankweller, D., Liberman, A. M., Fowler, C., \& Fischer, F. W. Phonetic segmentation and recoding in the beginning reader. In A. S. Reber \& D. Scarborough (Eds.), Toward a psychology of reading: The proceedings of the CUNY conference. Hillsdale, N.J: Erlbaum, 1977.

Mark, L. S., Shankweiler, D., Liberman, I. Y., \& Fowler, C. A. Phonetic recoding and reading difficulty in beginning readers. Memory \& Cognition, 1977, 5, 623-629.

Mattis, S., French, J. H., \& Rapin, I. Dyslexia in children and young adults: Three independent neuropsychological syndromes. Developmental Medicine and Child Neurology, 1975, 17, 150-163.

Miller, G. A., \& IsARD, S. Free-recall of self-embedded English sentences. Information and Control, 1964, 7, 292-303.

Perfetti, C. A., \& Goldman, S. Discourse memory and reading comprehension skill. Journal of Verbal Learning and Verbal Behavior, 1976, 15, 33-42.

Perfetti, C. A., \& Lesgoln, A. M. Discourse comprehension and sources of individual differences. In M. Just \& P. Carpenter (Eds.), Cognitive processes in comprehension. Hillsdale, N.J. Erlbaum, 1979.

Shankweiler, D., \& Liberman, I. Y. Exploring the relations between reading and speech. In R. M. Knights \& D. K. Bakker (Eds.), Neuropsychology of learning disorders: Theoretical approaches. Baltimore: University Park Press, 1976.

Shankweiler, D., Liberman, I. Y., Mark, L. S., Fowler, C. A., \& Fischer, F. W. The speech code and learning to read. Journal of Experimental Psychology: Human Learning and Memory, 1979, 5, 531-545.

SLosson, R. L. Slosson Intelligence Test for Children and Adults. New York: Slosson Educational Publications, 1963.

TzenG, O. J. L., Hung, D. L., \& WANG, W. S.-Y. Speech recoding in reading Chinese characters. Journal of Experimental Psychology: Human Learning and Memory, 1977, 3, 621-630.

Thorndike, E. L., \& Lorge, I. The teacher's word book of 30,000 words. New York: Bureau of Publications, Teachers College, Columbia University, 1944.

Vellutino, F. R., Steger, J. A., DeSetto, L., \& Phillips, F. Immediate and delayed recognition of visual stimuli in poor and normal readers. Journal of Experimental Child Psychology, $1975,19,223$

Vellutino, F. R., Steger, J. A., Kaman, M., \& DeSetto, L. Visual form perception in deficient and normal readers as a function of age and orthographic/linguistic familiarity. Cortex, $1975,11,22-38$

Weinstein, R., \& Rabinovitch, M. S. Sentence structure and retention in good and poor readers. Journal of Educational Psychology, 1971, 62, 25-30.

Wug, E. H., \& Roach, M. A. Immediate recall of semantically varied sentences by learning disabled readers. Perceptual and Motor Skills, 1975, 40, 119-125.

Woodcock, R. W. Woodcock Reading Mastery Tests. Circle Pines, Minn: American Guidance Services, 1973.

\section{APPENDIX \\ SENTENCE REPETITION MATERIALS}

Meaningful, Phonetically Nonconfusable Versions

1. Tom and Bill piled books on the chair in front of the door.

2. Don't play all the time at the teacher's chair or Miss Smith will get mad.

3. Poor Jim played inside when the snow covered up the back yard.

4. Kim saw that the big doll in the old barrel belonged to her.

5. Mondays at four, Johnny is able to play baseball with Mike and Bert.

6. Peg's brown dog bit at the bone that fell on the clean floor.

7. Sam drank a coke and a glass of fruit punch that Joan made.

\section{Meaningful, Phonetically Confusable Versions}

1. Jack and Mack stacked sacks on the track in back of the shack.

2. Don't roar any more at the store's door or Miss Moore will get sore.

3. Plain Jane remained in Spain when the rain washed out the main lane.

4. Lou knew that the blue shoe in the new canoe belonged to you.

5. Tuesdays at three Lucy is free to see TV with Dee and Lee.

6. Pat's bad cat bat at the rat that sat on the flat mat.

7. Kate ate a steak and a plate of date cake that Jake baked 


\section{Meaningless, Phonetically Nonconfusable Versions}

1. Sam and Chuck fried words on the leaf inside of the month.

2. Don't slip every time at the thought's top or the pill will get rushed.

3. Cool smells stopped in sand when the duck made up the green sink.

4. Jean saw that the right bush in the clean barn belonged to him.

5. Sometimes at lunch, Mary is thick to show first socks with grass and fish.

6. Bob's fried cap laughed at the chair that stood on the smart glass. tied.

\section{Meaningless, Phonetically Confusable Versions}

1. Fred and Ed read sleds on the thread instead of the bed.

2. Don't sing anything at the ring's sting or the king will get winged.

3. Paid spades stayed in shade when the maid wrote down the suede braid.

4. Ted read that the dead thread in the lead bread belonged to bed.

5. Often at ten, Martin is thin to spin twin men with skin and chin.

6. Kay's gray hay stayed at the clay that lay on the gay day.

7. Lou threw a glue and a shoe of blue stew that Sue grew.

(Received for publication September 18, 1979; revision accepted January 24,1980 .) 